\title{
EDUCAÇÃO E CONTRADIÇÃO NO CAMPO: E AS ESCOLAS PÚBLICAS?
}

\author{
EDUCACIÓN Y CONTRADICCIÓN EN EL CAMPO: ¿Y LAS ESCUELAS PÚBLICAS?
}

\author{
EDUCATION AND CONTRADICTION IN THE COUNTRYSIDE: HOW ARE THE \\ PUBLIC SCHOOLS?
}

\author{
Maria Antônia de SOUZA ${ }^{1}$
}

\begin{abstract}
RESUMO: Este artigo apresenta os resultados de uma pesquisa realizada em dez municípios de grande extensão territorial no estado do Paraná, com o intuito de compreender a política educacional em relação às escolas públicas rurais. Neste texto, selecionamos oito municípios considerados extremamente rurais para expor contradições presentes no campo e na educação, a partir de estudos documentais e entrevistas. O objetivo é problematizar microrregiões cujo território tem a presença de grandes propriedades e do agronegócio, ao lado do trabalho dos diversos povos do campo. Nesses contextos, há desafios na garantia do direito à educação. São marcados pelo fechamento de escolas, precariedade das estradas, centralidade do transporte escolar, dificuldade com a continuidade dos professores nas escolas etc. Conclui-se que a contradição que gera processos excludentes no campo reside na concentração da terra, na produção agrícola para exportação que pouco gera empregos, e decorre na política de fechamento de escolas que se fundamenta no reduzido número de estudantes. Ao estudar tais contextos regionais, evidencia-se a necessidade de outro projeto para o campo, de reforma agrária e políticas públicas para permanência dos sujeitos no campo.
\end{abstract}

PALAVRAS-CHAVE: Educação. Contradição. Campo. Escola pública. Educação do campo.

RESUMEN: Este artículo presenta los resultados de una investigación realizada en diez municipios de gran extensión territorial en el estado de Paraná, con el objetivo de comprender la política educativa con relación a las escuelas públicas rurales. En este texto, seleccionamos ocho municipios considerados extremadamente rurales para exponer las contradicciones presentes en el campo y en la educación, a partir de estudios documentales y entrevistas. El objetivo es problematizar las microrregiones cuyo territorio tiene la presencia de grandes propiedades y agroindustrias, al lado del trabajo de los diversos pueblos del campo. En estos contextos, existen desafios en la garantía del derecho a la educación. Están marcadas por cierres escolares, precarias carreteras que dan acceso a la sede municipal, centralidad del transporte escolar para los estudiantes, dificultad con la continuidad de los docentes en las escuelas, entre otras. Es posible concluir que la contradicción que genera procesos excluyentes en el campo reside en la concentración de la tierra, en la producción agrícola para la exportación que genera pocas oportunidades laborales, y resulta en la política de cierre de escuelas por lo bajo numero de estudiantes. Al estudiar estos contextos regionales, se evidencia la necesidad de otro proyecto de campo, reforma agraria y políticas públicas para que los sujetos permanezcan en el campo.

PALAVRAS CLAVE: Educación. Contradicción. Campo. Escuela pública. Educación rural.

${ }^{1}$ Universidade Tuiuti do Paraná (UTP), Curitiba - PR - Brasil. Professora no Programa de Pós-Graduação em Educação (UTP). Professora no curso de Pedagogia e do PROFEI (UEPG) - Ponta Grossa. Doutorado em Educação (UNICAMP). ORCID: https://orcid.org/0000-0001-7514-8382. E-mail: maria.souza8@utp.br 
ABSTRACT: This article presents the results of a research carried out in ten municipalities of great territorial extension in the state of Paraná, with the aim to understand the educational policy in relation to rural public schools. In this text, we selected eight municipalities considered extremely rural to expose contradictions present in the field and in education, based on documentary studies and interviews. The aim is to problematize microregions whose territory has the presence of large properties and agribusiness, alongside the work of the diverse peoples of the countryside. In these contexts, there are challenges regarding the guarantee to the right to education. They are marked by school closures, precarious roads that give access to the municipal headquarters, centrality of school transport for students, difficulty with the continuity of teachers in schools, among others. It is possible to conclude that the contradiction that generates exclusionary processes in the countryside resides in the concentration of land, in agricultural production for exportation that generates few job opportunities, and results in the policy of closing schools due to the low population density. When studying such regional contexts, it is evident the need for another project for the countryside, agrarian reform and public policies for the subjects to remain in the countryside.

KEYWORDS: Education. Contradiction. Countryside. Public school. Rural education.

\section{Introdução}

A Educação do Campo deixa marcas na educação brasileira desde 1998, com a formação de coletivos nacionais e estaduais, as conferências, as lutas e resistências para construção e continuidade de políticas educacionais, as experiências de formação de educadores inicial e continuada, os manifestos a favor da educação pública e gratuita, a produção bibliográfica coletiva e individual, a defesa de um projeto de sociedade que valorize o trabalho no campo, nas águas e nas florestas, que tenha os sujeitos diversos como protagonistas das políticas e práticas educacionais. Trata-se de processo de resistência e proposição de pautas coletivas para a formação educacional ampla dos povos do campo, da Educação Básica à pós-graduação stricto sensu. Não está reduzido à escola pública, no entanto, a coloca no centro do debate ao interrogar as políticas, o currículo, a organização do trabalho pedagógico, a identidade da escola e o vínculo dela com as questões inerentes aos povos do campo, das águas e das florestas.

Neste artigo, o objetivo é descrever municípios de ampla extensão territorial e identificar os seus principais desafios educacionais. São apresentados resultados da pesquisa intitulada Realidade das escolas públicas localizadas no campo no estado do Paraná: políticas educacionais, ruralidades e a efetivação do direito à educação, realizada no período de 2015 a 2017, com financiamento do CNPq, Edital Universal de 2014. Os dados demográficos, agrários, econômicos e educacionais foram atualizados em 2020, mediante 
estudo dos relatórios produzidos pelo Instituto Paranaense de Desenvolvimento Econômico e Social (Ipardes), em especial os cadernos municipais.

Investigamos os dez municípios paranaenses mais extensos territorialmente. São eles: Guarapuava, Tibagi, Castro, Ortigueira, Guaraqueçaba, Prudentópolis, Lapa, Cascavel, Ponta Grossa e Pinhão, conforme Ipardes (2020). Os municípios de Cascavel e Ponta Grossa, cuja densidade demográfica ultrapassa $150 \mathrm{hab} . / \mathrm{km}^{2}$, não foram considerados neste artigo. Portanto, são considerados os oito municípios marcadamente rurais, com núcleos urbanos pequenos e com relações socioeconômicas caracterizadas pelo trabalho no campo e nas águas, com comunidades quilombolas, faxinalenses, indígenas, acampados, assentados, cipozeiras, pequenos agricultores, pescadores, entre outros, em contraste com as atividades monocultoras em grandes extensões territoriais. São territórios com baixa densidade demográfica, agricultura familiar, áreas de proteção ambiental e aspectos culturais marcados por sociabilidade e religiosidade, além da expressiva concentração da terra e da produção agroexportadora. Neles há conflitos fundiários e se evidencia o que Fernandes, Welch e Gonçalves (2014) denominam de Brasil agrário paradoxal.

A pesquisa, de natureza documental, foi enriquecida com entrevistas realizadas com equipes gestoras municipais. Foram analisados os planos municipais de educação, planos diretores e relatórios fornecidos pelas secretarias municipais de educação. Teoricamente, o parâmetro de análise foi a Educação do Campo, suas conquistas, normativas, manifestos, e a concepção de campo como lugar de vida, diversidade, trabalho e cultura, movimentados na contradição do modo de produção capitalista, expressa na concentração da riqueza e nas disputas político-pedagógicas em torno da educação.

O artigo está estruturado em três partes, sendo a primeira uma explanação sobre os dez municípios pesquisados. A segunda apresenta um panorama territorial de oito municípios extensos, pontuando suas ruralidades e aspectos educacionais. A terceira trata da educação e contradição no campo, com problematização das escolas públicas. O parâmetro para a problematização dos aspectos educacionais é o conjunto de princípios da Educação do Campo construídos nos movimentos sociais.

\section{O campo nos municípios de grande extensão territorial}

O Brasil é composto por 5.570 municípios, com um total de $8.510 .295,914 \mathrm{~km}^{2}$. No país, há municípios com extensão territorial de $3,5 \mathrm{~km}^{2}$, como é o caso de Santa Cruz de Minas/MG, e com extensão de $159.000 \mathrm{~km}^{2}$, como é o caso de Altamira/PA, segundo dados 
do IBGE (2020). A extensão territorial dos oito municípios paranaenses estudados varia entre 2.000 e $3.163,44 \mathrm{~km}^{2}$. O estado do Paraná é formado por 399 municípios, agrupados em dez regiões geográficas caracterizadas pelo Ipardes (2020).

Municípios extensos territorialmente tendem a ter concentração da terra e da propriedade, que se somam à produção de grãos e pecuária destinados à exportação. Registram baixa densidade demográfica. A concentração fundiária e a frágil política de apoio aos agricultores familiares reforçam os processos migratórios em direção às cidades, especialmente por parte da juventude do campo, bem como intensificam os conflitos agrários. Além disso, outros fatores, como ausência de espaços de lazer e o fechamento de escolas têm contribuição para a saída dos jovens do campo. O Ensino Médio, por exemplo, tem oferta reduzida no campo. Os estudantes enfrentam o transporte escolar, que, por sua vez, possui redes complexas nos municípios, com longas rotas e domínio empresarial local. A Figura 1 permite a visualização das dez regiões e dos dez municípios paranaenses de maior extensão territorial.

Figura 1 - Mapa dos 10 municípios de maior extensão territorial do Paraná

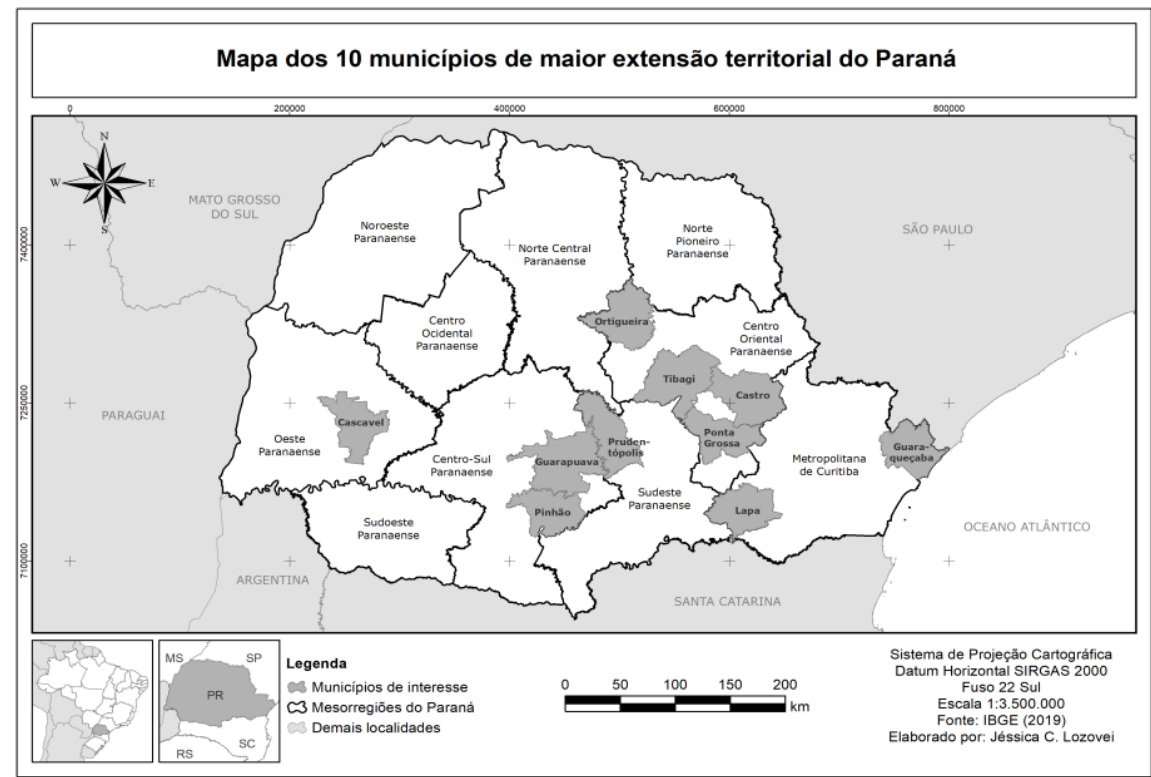

Fonte: IBGE (2019)

É possível observar que as regiões Centro-Oriental e Centro-Sul possuem o maior número de munícipios com grande extensão. Neles, tem havido conflitos fundiários e atuação do MST, em luta por reforma agrária.

A Tabela 1, adiante, registra a extensão, a densidade demográfica, a população do campo e da cidade, as escolas públicas urbanas e rurais. Excetuando Cascavel e Ponta Grossa, os municípios são marcados por baixa densidade demográfica e por atividades agrícolas 
centradas na agricultura familiar, agroflorestal e produção de grãos. A análise dos territórios rurais requer o olhar para os sujeitos, o trabalho, os usos do solo, a densidade demográfica e os conflitos fundiários, além de outros fatores como a política local, a dimensão sociocultural e socioambiental.

O município de Guaraqueçaba, como se verifica na Tabela 1, é o que possui menor densidade demográfica, com riqueza de diversidade socioambiental, porém classificado em $396^{\circ}$ lugar no Índice de Desenvolvimento Humano (IDH), ou seja, o quarto pior índice no estado. É o segundo município com maior número de escolas no campo e nas águas, haja vista que ele comporta várias ilhas. É o único em que a produção agropecuária predominante é de lavoura permanente, com destaque para a banana e o palmito.

Tabela 1 - Os dez municípios paranaenses de maior extensão territorial

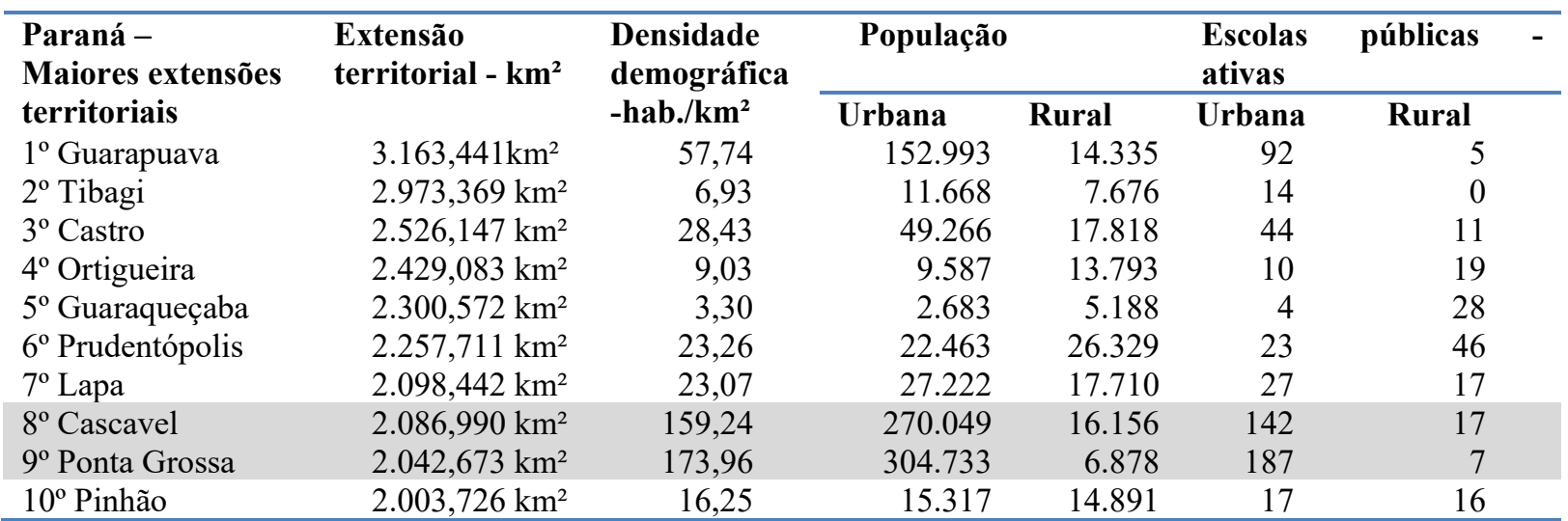

Fonte: MEC/INEP (2020) ${ }^{2}$

A maioria das escolas públicas rurais pertence à rede municipal de ensino. As escolas estaduais funcionam, predominantemente, em dualidade administrativa. Todos os municípios mencionados na Tabela 1 tiveram escolas fechadas no campo, a partir da década de 1990. O fechamento de escolas no campo, mais do que uma decisão política, é expressão da contradição entre um projeto de campo altamente mecanizado, com concentração da terra e produção de grãos, e um projeto de campo sustentável, como lugar de trabalho e moradia, com produção de diversidade de lavouras, sendo a maioria para o mercado interno. No campo da produção agroexportadora não há espaço para a juventude rural e nem para a diversidade de povos, embora os movimentos sociais e as comunidades mantenham-se firmes nos processos de resistência e luta pela permanência no seu lugar de trabalho, moradia e de vida.

\footnotetext{
${ }^{2}$ Números de Escolas: Disponível em: https://www.gov.br/inep/pt-br/acesso-a-informacao/dados-abertos/inepdata/catalogo-de-escolas. Acesso em: 30 nov. 2020. Densidade demográfica e dados da população: Disponível em http://www.ipardes.pr.gov.br/Pagina/Cadernos-municipais. Acesso: 29 nov. 2020
} 
O campo da produção das riquezas agrícolas, pecuárias, turísticas, é o mesmo das menores taxas de escolaridade. Dezenas de pesquisas educacionais indicam as desigualdades no campo, pois nele estão as escolas que não possuem bibliotecas, laboratórios e acesso à internet, maior distorção idade-série, menor escolaridade da população etc. Tais desigualdades são expressão de processos sociais contraditórios e históricos no Brasil, de acumulação de riqueza e pobreza, de construção de políticas públicas compensatórias ou paliativas, que não modificam os condicionantes estruturais socioeconômicos e políticos.

Compreendemos o campo, em concordância com o que escreve Verde (2004), sobre as quatro dimensões a serem consideradas na análise territorial. A espacial, que se refere a um continuum de relações rural-urbano, de atividades agrícolas, não-agrícolas, novas possibilidades de obtenção de renda e de reorganização do trabalho no campo. A ambiental, que se articula com atividades agropecuárias e com as áreas de proteção ambiental; lugares que não realizam produção agropecuária podem desenvolver atividades de turismo rural. A densidade demográfica, que estabelece número de hab. $/ \mathrm{km}^{2}$ para dizer da ruralidade do território; municípios com até 20 mil habitantes ou com até 80 hab. $/ \mathrm{km}^{2}$ podem ser considerados rurais no Paraná. E a cultural, que diz respeito ao patrimônio cultural construído em determinado espaço pela coletividade que nele vive, as ações, manifestações, a maneira como as comunidades vivem o cotidiano, que atravessa tempos e espaços.

Além desses elementos, acrescentamos a diversidade de povos do campo, das águas e das florestas. O estado do Paraná possui trajetória de conflitos por terra, lutas por reforma agrária, contra a construção de barragens, e tem fortalecido a identidade dos povos tradicionais como os Quilombolas e os Faxinalenses. Fernandes, Welch e Gonçalves (2014, p. 21) compreendem que "O Brasil agrário é paradoxal porque $74 \%$ dos agricultores recebem somente $15 \%$ do crédito agrícola, possuem apenas $24 \%$ da área agricultável [...]". Em contraste, “[...] o agronegócio fíca com $85 \%$ do crédito agrícola, controla $76 \%$ da área agricultável $[\ldots]$ ".."

Portanto, para dizer do campo é preciso destacar os sujeitos que nele resistem em contraste com o avanço do capitalismo agrário, mediante exploração de florestas e produção de grãos, em particular.

\section{Panorama territorial dos oito maiores municípios rurais do Paraná}

Os oito municípios investigados podem ser compreendidos levando em conta o trabalho no campo, com destaque para os números de estabelecimentos rurais e a sua 
ocupação. Selecionamos algumas categorias utilizadas pelo Ipardes (2020) para demonstrar a ruralidade, a saber: quantidade de estabelecimentos agropecuários, sua extensão, a condição do produtor e o tipo de produto cultivado. Os estabelecimentos agropecuários são ocupados com lavoura temporária, horticultura e floricultura, lavoura permanente, produção de sementes e mudas, pecuária e criação de outros animais, produção de florestas plantadas, produção florestal de florestas nativas, pesca e aquicultura.

O município de Guarapuava, maior em extensão territorial do estado, está localizado na Região Centro-Sul do Paraná. Encontra-se em $78^{\circ}$ lugar em IDH $(0,731)$ no estado. Possui 2.134 estabelecimentos agropecuários, em área de 207.561 hectares (ha). São 116.492 ha que contêm 890 estabelecimentos ocupados com lavoura temporária, sendo a maioria de soja, milho, cevada e trigo. São 44.991 ha que contêm 873 estabelecimentos de pecuária e criação de outros animais. Possui 33.708 ha com 105 estabelecimentos de produção florestal plantada. São 1.893 proprietários de terra que detêm 191.305 ha. Há 105 assentados sem titulação definitiva. Os demais 136 estabelecimentos estão com arrendatários, parceiros, em sistema de comodato e ocupantes. No município, a lavoura permanente concentra-se em frutas e ervamate. Trata-se de um município rural, embora o IBGE (2010) registre o grau de urbanização como sendo 91,43\%. Nela há 5 distritos, que são: Atalaia, Entre Rios, Guairacá, Guará e Palmeirinha. O município possui comunidades indígenas, assentamentos rurais e comunidades Quilombolas.

Como o maior município em extensão territorial tem apenas 5 escolas no campo, segundo o Inep (2020)? A explicação reside na concentração da terra, como se observa na descrição anterior: mais da metade da área agricultável é ocupada com lavoura temporária, centralmente grãos. Há povos do campo dispersos no território, que resistem na agricultura com produção em pequenas áreas, fator que deveria ser considerado na construção das políticas públicas.

Tibagi é o segundo maior município em extensão territorial do Paraná, localizado na Região Centro-Oriental. Encontra-se em $338^{\circ}$ lugar em IDH (0,664). Possui 1.040 estabelecimentos agropecuários, em 228.252 ha, sendo 557 estabelecimentos de lavoura temporária (soja, trigo, milho e feijão predominantemente), ocupando 150.120 ha. São 366 estabelecimentos de pecuária e criação de outros animais, em 33.101 ha. Há 64 estabelecimentos de produção florestal de florestas plantadas em 43.826 ha. A lavoura permanente ocupa em torno de 700 ha, que contêm 21 estabelecimentos que produzem laranja, maçã, pêssego e tangerina. Dos 1.040 estabelecimentos, 928 pertencem a proprietários, com total de 214.311 ha; 30 pertencem a assentados sem título definitivo, em 
área de 549 ha, e 82 estabelecimentos estão na condição de arrendamento, parceria, comodato e ocupação. Nota-se que mais de $50 \%$ da produção é de lavoura temporária, que ocupa mais de $60 \%$ das terras agricultáveis. O município possui 2 distritos administrativos no campo, que são Alto do Amparo e Caetano Mendes. Possui comunidades Quilombolas e assentamentos rurais. É um município eminentemente rural, embora para o IBGE (2010) o grau de urbanização seja de 60,32\%. Reitera-se a mesma pergunta feita para o município de Guarapuava: Como Tibagi não registra escola no campo, segundo dados do INEP (2020)? Quanto tempo os jovens do campo ficam no transporte escolar?

Em entrevista com a equipe pedagógica municipal, em 2015, foi informado que há estudantes que permanecem três horas no transporte escolar. São 75 linhas destinadas ao transporte escolar, sendo 39 pertencentes a 21 empresas terceirizadas e 36 linhas de transporte municipal. São $10.000 \mathrm{~km}$ de percurso diário intracampo, sendo $4.741 \mathrm{~km}$ percorridos pelo transporte terceirizado. Durante longos períodos de chuva, os estudantes não chegam à escola, pois as estradas ficam intransitáveis. A equipe também informou haver 5 escolas rurais, sendo 3 municipais e 2 estaduais. O município possui 4 assentamentos rurais organizados no Movimento dos Trabalhadores Rurais Sem Terra (MST). As crianças de 2 assentamentos frequentam escola urbana. Nota-se dificuldade em relação à identidade das escolas do campo. As secretarias municipais tendem a classificar as escolas dos distritos como sendo urbanas. No entanto, pela discussão consolidada nas diretrizes nacionais e no movimento nacional de Educação do Campo, a identidade do campo é dada pelo vínculo da escola com as questões da comunidade, com os sujeitos do campo. Verifica-se que os povos do campo ficam invisibilizados em meio à produção agropecuária em larga escala e às relações políticas locais.

Castro é o terceiro maior município em extensão territorial, localizado na Região Centro-Oriental paranaense. Encontra-se em $220^{\circ}$ na classificação do IDH do estado, com índice de 0,703. Possui 2.603 estabelecimentos agropecuários, em área total de 140.569 ha. A lavoura temporária (soja, trigo, feijão e milho, prioritariamente) está em 807 estabelecimentos e ocupa uma área de 65.980 ha. Os estabelecimentos de pecuária e criação de outros animais somam 1.536, em uma área de 54.956 ha. A produção florestal de florestas plantadas está em 98 estabelecimentos, em área de 17.776 ha. A lavoura temporária está em 89 estabelecimentos, em área total de 1.270 ha, e a produção de horticultura e floricultura em 53 estabelecimentos, com área de 336 ha. São 2.232 proprietários, em área total de 126.862 ha; 41 assentamentos sem titulação definitiva, em área de 1.766 ha; 78 arrendatários, em área de 5.090 ha; 35 parceiros, em área de 3.292 ha; 191 comodatos, em área de 2.874 ha; e 6 
produtores sem área. Integra uma região conhecida como bacia leiteira no estado. Pecuária e lavoura temporária ocupam uma área de 120.000 ha, praticamente $85 \%$ do uso do solo se destinam a tais atividades econômicas.

O município possui 2 distritos no território rural, Abapã e Socavão. Nele, há comunidades Quilombolas, pequenos agricultores, assentados e acampados do MST. Trata-se de um município eminentemente rural, em que pese para o IBGE (2010) o grau de urbanização ser de 73,44\%. Nos anos de 1990, o município possuía mais de 120 escolas no campo. Com a política de nucleação de escolas, foram fechadas aproximadamente 100 escolas no campo, expressando com isso que o campo perdeu população e/ou que a política de transporte escolar passou a ter ênfase intracampo e do campo para a cidade. O Inep (2020) registra 11 escolas rurais, sendo 9 municipais e 2 estaduais. O transporte escolar, segundo a secretária de educação em entrevista no ano de 2015, tem um investimento anual de $\mathrm{R} \$ 8.300 .000$, dos quais $\mathrm{R} \$ 482.226,28$ são oriundos do Governo Federal, através do PNATE (Programa Nacional de Apoio ao Transporte do Escolar), R \$2.000.000 do Governo do Estado do Paraná, através do PETE (Programa Estadual de Transporte Escolar), e R\$5.817.773,72 do próprio município. O transporte escolar atendia, no ano de 2015, a 4 mil alunos.

A equipe pedagógica destacou que o critério para a escola ser considerada "do campo" é a inexistência de diretor, enquanto escolas urbanas são assim cadastradas porque possuem diretores. Novamente, constata-se a dificuldade em construir a identidade da escola do campo e, portanto, de reconhecer a diversidade de povos existentes no território.

O município de Ortigueira é o quarto maior em extensão territorial do Paraná, localizado na Região Centro-Oriental. Possui IDH de 0,609, encontrando-se na $391^{\text {a }}$ posição no estado do Paraná. Os estabelecimentos agropecuários são 2.968 e ocupam uma área de 208.814 ha. Atividades de pecuária e criação de outros animais estão em 1.801 estabelecimentos, em área de 105.088 ha. A lavoura temporária (soja, trigo, milho e feijão) está em 932 estabelecimentos, em área de 59.617 ha. A produção florestal de florestas plantadas está em 112 estabelecimentos, em área de 41.698 ha. Há 90 estabelecimentos de horticultura e floricultura e 25 de lavoura permanente, que ocupam 2.012 ha. São 2.465 proprietários de terras, com total de 189.803 ha; 83 arrendatários, em área de 4.252 ha; 116 assentados sem titulação definitiva, em área de 2.075 ha; 220 ocupantes, em área de 10.895 ha, estando o restante em comodato, parceria ou situação de produtor sem área registrada. $\mathrm{O}$ município tem 4 distritos, que são: Barreiro, Lajeado Bonito, Monjolinho e Natingui. Possui comunidades de assentados rurais e indígenas. Possui 26 instituições escolares no campo, entretanto também é o que apresenta o maior número de escolas fechadas na última década, 
em torno de 120 instituições. Escolas rurais em atividade são 19, sendo 10 municipais e 9 estaduais. Estão organizadas em dualidade administrativa. A equipe pedagógica do município informou que 7 escolas de comunidades rurais realizam suas atividades de forma multisseriada, onde o professor leciona, limpa a escola e cozinha para os alunos. O município possui 2 escolas localizadas no Assentamento Libertação Camponesa, sendo uma instituição municipal de ensino e outra estadual; 2 instituições de administração estadual localizadas em terras indígenas: Posto Indígena Queimada e Mococa. São investidos $\mathrm{R} \$ 5.000 .000$ ao ano em transporte escolar, sendo 237 linhas e 96 veículos que realizam o transporte diário de 4.391 estudantes, tanto de escolas municipais quanto estaduais, e para universitários com destino à Telêmaco Borba, Apucarana, Jandaia do Sul e Arapongas. As linhas são operadas, na grande maioria, por empresas terceirizadas. Os dados expressam que são 13 empresas terceirizadas responsáveis por 212 linhas, com um gasto diário estimado em $\mathrm{R} \$ 15.599,41$. A frota municipal opera em 25 linhas. Esses dados, fornecidos pela Secretaria Municipal de Educação, referem-se ao ano de 2011. É o segundo município, conforme o IBGE (2010), com grau de urbanização abaixo de 50\%, sendo registrado em $41,01 \%$. A equipe pedagógica demonstra conhecimento dos princípios da Educação do Campo e estreita relação com as comunidades de assentamentos organizadas no MST.

Guaraqueçaba é o quinto município em extensão territorial, localizado na Região Metropolitana e Litoral paranaense. Possui IDH 0,587, encontrando-se na $396^{\mathrm{a}}$ posição, quarto pior índice do estado do Paraná. O município tem 493 estabelecimentos agropecuários, em área de 20.140 ha, sendo 203 estabelecimentos de cultura permanente (palmito e banana prioritariamente), em uma área de 9.618 ha; 92 estabelecimentos de pecuária e criação de outros animais, em área de 5.808 ha; 78 estabelecimentos de lavoura temporária (mandioca predominantemente), em área de 2.552 ha; 95 estabelecimentos de pesca, em 135 ha; 20 estabelecimentos de aquicultura, sem área definida; 2 estabelecimentos de floresta nativa e 1 de floresta plantada, sem área definida. São 450 proprietários de um total de 17.569 ha; 23 comodatos, em 1.894 ha; 10 estabelecimentos de arrendatários, assentados e parceiros sem área definida, e 10 ocupantes de 128 ha. O município possui os distritos de Ararapira e Serra Negra. É formado por ilhas, possui povos tradicionais do campo, Quilombolas, indígenas, pescadores, caiçaras, entre outros. O grau de urbanização é de 34,09\% de acordo com o IBGE (2010). Registra 21 escolas municipais, todas em unidades de uso sustentável, e 7 estaduais no campo, sendo 6 em unidade de conservação. Durante a gestão do governo Requião (2003 a 2010), foram construídos os projetos político-pedagógicos das escolas das ilhas no Paraná, com a participação da Articulação Paranaense por uma Educação do Campo. 
Prudentópolis é o sexto maior município em extensão territorial e localiza-se na Região Sudeste paranaense. Encontra-se em $312^{\circ}$ lugar em IDH no estado, com índice de 0,676. Tem um total de 6.625 estabelecimentos agropecuários, em área de 143.313 ha. São 5.145 estabelecimentos com lavoura temporária (soja, feijão, milho e trigo prioritariamente), cultivados em área de 97.005 ha. São 895 estabelecimentos de pecuária e outros animais, em uma área de 33.531 ha; 274 estabelecimentos com lavoura permanente (erva-mate prioritariamente), em 4.207 ha; 83 estabelecimentos de horticultura e floricultura, em área de 476 ha; são 147 estabelecimentos de produção florestal de florestas plantadas, em área de 6.974 ha. Os demais são estabelecimentos de produção florestal nativa e aquicultura. São 5.967 proprietários de 134.321 ha; 277 são arrendatários de área de 4.840 ha e 192 em comodato, com área de 1.419 ha. Há assentados sem titulação definitiva, parceiros e ocupantes sem área. Há comunidades assentadas, indígenas, Quilombolas e faxinalenses. Existem 2 distritos no território rural, Jaciaba e Patos Velhos. O município tem 46 escolas no campo, das quais 35 são multisseriadas. Todas as escolas estão cadastradas como "do campo", haja vista que reformularam os projetos político-pedagógicos no ano de 2014. O grau de urbanização é de 46,04\%, segundo o IBGE (2010).

O município da Lapa é o sétimo em extensão territorial, localizado na Região Metropolitana de Curitiba. Possui IDH de 0,706, e encontra-se no $199^{\circ}$ lugar no estado do Paraná. Possui 2.290 estabelecimentos agropecuários, em área de 116.743 ha. São 1.457 estabelecimentos com lavoura temporária (soja, feijão, trigo e milho prioritariamente), em uma área de 83.469 ha; 608 estabelecimentos de pecuária e criação de outros animais, em área de 20.917 ha; 43 estabelecimentos de produção de florestas plantadas, em área de 8.988 ha. Os demais são estabelecimentos com lavoura permanente, florestas nativas, aquicultura, horticultura e floricultura. São 1.983 proprietários de uma área de 104.276 ha; 96 arrendatários de área de 6.500 ha, e 87 assentados sem título definitivo, em área de 2.568 ha. No município, há 2 distritos no território rural: Água Azul e Mariental. São dezenas de comunidades do campo, distribuídas em assentados, Quilombolas, povos tradicionais faxinalenses e indígenas. No município está localizado o assentamento Contestado, organizado no MST, com a Escola Latino Americana de Agroecologia. Para o IBGE (2010), Lapa possui grau de urbanização de 60,58\%. Segundo o Inep (2020), o município da Lapa conta com 12 escolas rurais municipais e 5 escolas rurais estaduais. Dessas, 2 instituições escolares funcionam em um assentamento.

O município de Pinhão é o décimo em extensão territorial, localizado na Região Centro-Sul paranaense. Possui IDH de 0,654, ocupando a 354a posição no estado do Paraná. 
Possui 2.852 estabelecimentos agropecuários, em 134.909 ha. A lavoura temporária (soja, milho, cevada e trigo prioritariamente) ocupa 65.422 ha, distribuída em 1.047 estabelecimentos. Em 51.205 ha estão 1.351 estabelecimentos com pecuária e criação de outros animais; 23 estabelecimentos de lavoura permanente ocupam 1.500 ha. São 11.496 ha com produção florestal de florestas nativas, em 362 estabelecimentos, e 30 estabelecimentos de produção florestal plantadas, em 5.672 ha. Os demais estabelecimentos são ocupados com aquicultura, horticultura e floricultura. São 2.234 proprietários de 121.893 ha, estando o restante distribuído em 209 assentados sem título definitivo, em 4.468 ha; 175 parceiros, em 2.681 ha; 120 comodatos, em 3.012 ha; 92 ocupantes, em 2.140 ha; e 22 arrendatários, em 714 ha. O município possui 3 distritos, que são Bom Retiro, Faxinal do Céu e Pinhalzinho, e comunidades tradicionais, Quilombolas e indígenas. Segundo o IBGE (2010), a taxa de urbanização é de 50,71\%. O município possui 10 escolas rurais municipais e 6 escolas estaduais, das quais 3 são multisseriadas.

A equipe pedagógica informou a existência de uma escola em assentamento do MST e áreas de ocupação de terras e assentamentos, que são o Assentamento do Rocio e Salete, que formam um único assentamento. Possui 2 comunidades faxinalenses: Faxinal dos Ribeiros e Faxinal dos Coutos. O transporte escolar tem investimento de aproximadamente $\mathrm{R} \$ 5.000 .000$, sendo R $\$ 907.000$ de recursos do governo do estado do Paraná, através do PETE, e R\$450.000 do PNATE, governo federal. O município colabora com $\mathrm{R} \$ 2.980 .000$ anual para o transporte escolar. Para a equipe pedagógica, o município de Pinhão é eminentemente rural e até as escolas urbanas poderiam ter identidade do campo, haja vista que os alunos pertencem a diversas comunidades rurais.

Em síntese, a investigação que focaliza microrregiões permite identificar aspectos do território que ficam invisibilizados em análises estatísticas e de larga escala. Nos oito municípios supracitados, foi possível registrar a concentração da terra e da propriedade; a centralidade da produção agrícola em culturas temporárias como soja, milho, feijão, trigo e cevada, produzidas para exportação e altamente mecanizadas. Somente um município (Ortigueira) tem predominância de pecuária e criação de outros animais, e outro tem centralidade na produção de lavoura permanente (Guaraqueçaba). Os menores IDH municipais estão em regiões com concentração fundiária no Paraná, expressando contradição e desigualdade, marcas histórias do território e da sociedade brasileira.

São diversos sujeitos do campo, a exemplo de comunidades Quilombolas, assentados e acampados, faxinalenses, indígenas, praticantes de agricultura familiar e pescadores. A baixa densidade demográfica e a extensa rede de transporte escolar rural são marcas de todos os 
municípios, com reduzido número de escolas no campo. A maioria das instituições escolares é municipal e com reduzida presença do Ensino Médio, o que configura, portanto, prejuízos à juventude do campo.

O registro do IBGE sobre o grau de urbanização não condiz com a realidade socioeconômica e socioambiental, haja vista que, para o Instituto, somente 3 municípios dentre os pesquisados possuem menos de 50\% de grau de urbanização. Mascara-se a diversidade de povos do campo, das águas e florestas com números que exaltam o urbano no país. A classe subalternizada do campo e da cidade, extremamente resistente, é invisibilizada ou criminalizada, em nome da manutenção das relações de dominação inerentes ao modo de produção capitalista.

O financiamento da educação é utilizado, em grande medida, para o transporte escolar, com predomínio de empresas terceirizadas na execução desse serviço. As condições das estradas são mencionadas como difíceis e intransitáveis em dias chuvosos, deixando os estudantes sem acesso à escola, entre outras características. Nessas regiões geográficas que possuem imensos territórios municipais, quais são os principais desafios às políticas educacionais e à Educação do Campo?

\section{Educação e contradição no campo: e as escolas públicas?}

No estado do Paraná, segundo o INEP (2020), Catálogo de escolas, estão registradas 828 escolas municipais rurais, 125 em áreas de assentamentos, quilombolas, terras quilombolas e indígenas, totalizando 1.250 escolas no campo, entre as municipais e as estaduais. Entre os anos de 2014 e 2020 foram fechadas em torno de 1.000 escolas no campo, no estado. As determinações que geram o fechamento de escolas são várias, dentre elas destacam-se: o projeto de campo excludente que avança no país, centrado na produção agropecuária mecanizada, em extensas áreas e destinada à exportação; a concentração fundiária que fortalece a baixa densidade demográfica em inúmeros municípios brasileiros; a falta de apoio técnico, econômico e jurídico aos povos do campo e à juventude, gerando migração campo>cidade; políticas locais direcionadas a grandes investimentos econômicos e pautadas por relações clientelistas etc. Assim, o motivo aparente do fechamento de escolas é o reduzido número de estudantes. A raiz do problema está no projeto de campo e de país, que dá continuidade à reprodução de desigualdades e, também, aos enfrentamentos e resistências sociais no campo. 
Há expressiva produção acadêmica no Brasil e no Paraná sobre educação e escolas públicas no campo. No Brasil, segundo Souza (2016a; 2020), há centenas de teses e dissertações sobre Educação do Campo. Santos (2020) analisa a produção sobre Educação do Campo na região nordeste do Brasil e demonstra o crescimento da área, que se explica pelo aumento do número de programas de pós-graduação stricto sensu e de grupos de pesquisa. No Paraná, trabalhos recentes somam-se aos mencionados em Souza (2016a; 2020), a saber: Festa (2020) analisa as interfaces educação especial e Educação do Campo; Lima (2020) investiga os programas vinculados a empresas e entes paraestatais que são direcionados para as escolas públicas no campo; Paula (2019) investiga os significados da escola para uma comunidade de uma das ilhas do município de Guaraqueçaba; Reichenbach (2019) e Pereira (2017) analisam a política de fechamento de escolas no estado do Paraná e Cruz (2018), Pianovski (2017) e Rodrigues (2017) estudam escolas públicas do campo, aprendizagem em turmas multisseriadas e a reestruturação de projetos político-pedagógicos; Mariano (2016) analisa o trabalho com os complexos de estudo nas escolas itinerantes do Paraná, entre outros. São pesquisas que anunciam desafios no âmbito da política educacional e potencialidades das práticas pedagógicas nas escolas no/do campo.

A Articulação Paranaense Por Educação do Campo tem problematizado a política de fechamento de escolas no campo e encaminhado orientações para a luta contra essa política. Em que pese a existência da Lei $\mathrm{n}^{\mathrm{o}} 12.960$ de 2014 (BRASIL, 2014), que insere um parágrafo único no art. 28 da LDB 9.394/96 (BRASIL, 1996), a prática de fechar escola continua pautada no discurso do reduzido número de alunos por escola e na ampliação da rede de transporte escolar.

O que se observa na maior parte dos municípios é a política de nucleação de escolas, que extingue os estabelecimentos de pequeno porte e, com isso, recria relações pedagógicas com os estudantes e com as comunidades. Nas escolas de menor porte, há uma aproximação maior entre professores, estudantes e famílias. Segundo relatos de professoras idosas do campo, as escolas são extensão do ambiente familiar, além das relações entre famílias e professores, que são estreitas e de formação de laços de parentesco. No processo de nucleação, entra em cena a política de transporte escolar e a ampliação do tempo que os estudantes utilizam para ir e retornar da escola. Em períodos de chuvas, para os povos do campo, as estradas em condições precárias dificultam ou impedem a circulação dos veículos escolares. Nas ilhas, os nevoeiros dificultam o acesso de professores e estudantes às escolas.

Uma contradição que salta aos olhos na análise dos cadernos municipais (IPARDES, 2020) é a presença de centenas de estabelecimentos rurais que produzem grãos e dezenas que 
produzem lavoura permanente, como frutas e verduras, por exemplo. Nesse contexto, identifica-se a ideologia da negação da ruralidade municipal e/ou a sua identificação com o atraso tecnológico. Exaltam-se as atividades vinculadas ao agronegócio realizado em grandes estabelecimentos rurais e para a exportação, ao passo que pouca visibilidade e incentivos se atribuem aos povos do campo e à agricultura familiar.

Outra contradição refere-se ao direito educacional que se efetiva mediante o deslocamento da maior parte das crianças e jovens para as cidades ou para escolas nucleadas no campo. Os municípios são rurais, porém todos os serviços públicos estão centralizados na cidade. Nesse sentido, os movimentos sociais do campo têm lutado contra a política de fechamento de escolas, pela valorização da formação dos profissionais, pela qualidade da educação e pelo fortalecimento da identidade dos povos do campo, pela formação para a produção agroecológica, pelo incentivo à juventude camponesa e sua permanência na terra, algo que depende da reforma agrária e do conjunto de políticas públicas necessárias à sua efetivação.

A negação do campo como lugar da diversidade e da agricultura familiar, do trabalho com as águas e as florestas, em contraste com a valorização das atividades agrícolas em grandes propriedades e o seu favorecimento constituem outra contradição. Reproduz-se a lógica do favorecimento daqueles que possuem o apoio técnico, financeiro e jurídico.

Desde 2002, estão em vigência diretrizes, decreto e leis que são frutos das lutas dos movimentos sociais pela Educação do Campo. Entretanto, as experiências coletivas de formação educacional não são conhecidas e nem reconhecidas na maior parte dos municípios brasileiros, em particular naqueles que não contam com a participação dos movimentos sociais do campo, das águas e das florestas. Conforme escrevem Machado e Vendramini (2013), os avanços são pequenos no que se refere ao financiamento da Educação do Campo, mesmo diante dos argumentos dos movimentos sociais. São poucos recursos para as escolas do campo, infraestrutura ainda precária, estradas de difícil acesso, instabilidade do quadro de educadores etc. Em que pese haver "[...] disposição dos educadores e da comunidade em estruturar um projeto educativo que contemple as aspirações de desenvolvimento coletivo, com perspectivas de trabalho para os jovens e de atendimento às necessidades socioculturais da comunidade" (MACHADO; VENDRAMINI 2013, p. 6), ela esbarra nas dificuldades mencionadas.

O que se constata nos municípios é a infraestrutura escolar, tecnológica e estradas em condições precárias. Há escolas que estão há anos sem manutenção, pois os recursos para as escolas do campo, especialmente aquelas com poucos alunos, são insuficientes diante das suas 
necessidades, tais como bibliotecas, laboratórios de informática, internet, sala de professores, linhas telefônicas, equipamentos audiovisuais, mobiliários etc. Nesses municípios, é comum visualizar antigos prédios escolares, ou o que sobrou deles, às margens das estradas ou em meio à pastagem. Com a precariedade de infraestrutura das escolas, pergunta-se: e os alunos da educação especial?

Nozu, Bruno e Heredero (2016) lançam indagações sobre as escolas do campo em relação à educação especial. Uma delas refere-se ao atendimento especializado nas salas de recursos multifuncionais, em que os autores questionam se esse atendimento tem sido realizado com base nas premissas de existência do homem do campo ou tem reproduzido um modelo de educação especial 'urbanocêntrico'? Sobre o mesmo tema, Festa (2020) analisa que a interface da educação especial com a Educação do Campo ocorre no plano das lutas sociais, da política nacional e das diretrizes curriculares, mas ainda estão distantes de efetivar os princípios da Educação do Campo. São fragilidades de toda natureza, desde materiais didáticos até a formação docente, da infraestrutura da escola ao transporte escolar, pouco ou nada adaptado às necessidades especiais. Avança-se no arcabouço normativo e de legislação no campo dos direitos sociais, entretanto, os sujeitos do campo resistem nos seus territórios, criam alternativas para o estudo dos filhos e a superação dos obstáculos.

Sobre o material didático, à época da pesquisa, 2015, as escolas tinham recebido o material do Programa Nacional do Livro Didático Campo (PNLD-Campo), que, segundo equipes pedagógicas, tinha pouca aderência à Educação do Campo, era frágil em conteúdos e atividades. Destacam a presença de materiais de entidades paraestatais, como o Serviço Nacional de Aprendizagem Rural (SENAR), conhecido como Programa Agrinho, que tem ampla divulgação no estado do Paraná, porém com conteúdo vinculado a uma concepção de desenvolvimento como sinônimo de agronegócio, mecanização agrícola e produção para exportação. Embora o programa seja refutado pela Articulação Paranaense Por Educação do Campo e exista nota recomendatória do Ministério Público do Paraná de não uso do Agrinho nas escolas, ele continua presente na cidade e no campo. Na contramão da Educação do Campo, como analisa Lima (2020), estão os materiais financiados com dinheiro público e que pouco ou nada valorizam os povos do campo, das águas e das florestas, e seu modo sustentável de lidar com a natureza. São povos com experiências individuais e coletivas de relação com a natureza, cujos conhecimentos podem enriquecer o trabalho pedagógico, porém eles ainda são tratados como "atrasados".

A organização pedagógica escolar, em especial na rede municipal, é multisseriada. A ela é atribuída a ideia de ensino de baixa qualidade, entretanto, em regiões de baixa densidade 
demográfica, há a necessidade de rever o trabalho pedagógico, no sentido do que defende Hage (2014) sobre a transgressão do paradigma da (multi) seriação como referência para a construção da escola do campo.

Há municípios que não possuem as próprias propostas curriculares e seguem os Parâmetros Curriculares Nacionais (PCNs), ao passo que outros terceirizam suas propostas, isto é, contratam empresas para realizar essa tarefa. Os conteúdos trabalhados estão distantes das práticas sociais, pois o trabalho no/do campo quase não é problematizado na sala de aula e, quando é debatido, não apresenta a contradição relacionada à estrutura agrária brasileira, a concentração da propriedade, de um lado, e a pobreza e resistência dos povos tradicionais do campo, de outro lado. No ano de 2020, os municípios têm discutido a Base Nacional Comum Curricular (BNCC) e alguns têm feito indagações sobre "o que há sobre educação dos povos do campo, diversidade e interdisciplinaridade na BNCC?".

Uma condição que permanece nos municípios é o processo conhecido como rotatividade de professores. Equipes pedagógicas mencionam que há professores que moram na cidade e se deslocam para o campo, para trabalho em mais de uma escola; há professores que não são concursados e que trocam de escola a cada ano; professores que pedem locomoção de escola devido à dificuldade de acesso à escola e falta de ajuda de custo. Afirmam que as condições precárias de trabalho interferem no processo ensino-aprendizagem e no estabelecimento de vínculo com a comunidade. Como os professores ficam pouco tempo nas escolas, é imprescindível uma política de formação continuada que seja ofertada de maneira diferente dos tradicionais cursos de especialização realizados a distância e distantes da realidade do campo. Uma formação com os professores mediada por grupos e núcleos de pesquisas das universidades pode ser um dos caminhos na valorização do profissional e dos conhecimentos. As pesquisas têm revelado que professores e gestores possuem pouco conhecimento preliminar sobre os princípios da Educação do Campo, das políticas, das contradições históricas e das lutas sociais dos povos do campo. Dois princípios são fundamentais: a identidade da escola construída coletivamente com a participação da comunidade organizada e a articulação com um projeto popular de país.

No âmbito da Educação do Campo, Caldart (2004, p. 28) escreve sobre um traço essencial do projeto político e pedagógico da Educação do Campo, ou seja, "trata-se de uma educação dos e não para os sujeitos do campo. Feita, sim, por meio de políticas públicas, mas construídas com os próprios sujeitos dos direitos que as exigem”. Dessa forma, o projeto com caráter emancipatório exige a participação efetiva dos povos do campo. 
Por fim, dois aspectos que merecem atenção nos municípios marcadamente rurais são: de um lado, a Educação Infantil e o Ensino Médio, cuja oferta é insuficiente. Educação Infantil, na maioria das vezes, acontece junto com o Ensino Fundamental, anos iniciais. Para cursar o Ensino Médio, a maioria dos jovens tem que sair do campo. De outro lado, a atenção às pessoas idosas do campo, haja vista que há um número expressivo de aposentados vivendo no campo, em condições de total insegurança e frágil atendimento de saúde, bem como de locomoção para os núcleos urbanos. A contradição é evidente: no campo, onde há predomínio do agronegócio, as pessoas que lá vivem estão "esquecidas” pelo poder público local, estadual e nacional. Valoriza-se a tecnologia para o desenvolvimento, mas ela é negada aos povos do campo quando não são incentivadas políticas públicas e pesquisas voltadas para a qualidade de vida dos povos que têm uma vida toda no campo, nas águas ou florestas.

Importante registrar que a realidade educacional rural vivida no Brasil é semelhante em outros países da América Latina, que têm constituído coletivos que lutam pela valorização dos conhecimentos dos povos do campo, em especial os indígenas. Estudos microrregionais podem fortalecer resistências locais, nacionais e internacionais. $\mathrm{O}$ que os movimentos sociais defendem no Brasil como Educação do Campo tem relação com a concepção crítica de educação rural presente em países como Peru e Colômbia, por exemplo. A concentração fundiária e a negação dos conhecimentos dos povos tradicionais do campo são lutas latinoamericanas. Conhecer e reconhecer os territórios locais pode fortalecer a construção de outro projeto societário, bem como da reforma agrária popular defendida pelo MST e Via Campesina.

\section{Considerações finais}

Este artigo tem o propósito de problematizar os municípios paranaenses com ampla extensão territorial e evidenciar aspectos da política educacional no campo. Seu caráter descritivo, ao tratar dos oito municípios, busca provocar análises educacionais pautadas na estrutura agrária, nos usos do solo e nos conflitos agrários. Por exemplo, as lutas contra o fechamento de escolas não se esgotam na política educacional, elas interrogam a estrutura agrária e o projeto político-econômico que excluem os povos do campo. Foi possível constatar que há regiões geográficas que possuem vários municípios extensos, como é o caso da Centro-Oriental, com Castro, Ortigueira e Tibagi. Neles, é visível a concentração da terra, o baixo IDH e a baixa densidade demográfica. O menor IDH é do município de 
Guaraqueçaba, região de unidades de conservação ambiental, onde estão povos pescadores e indígenas. É o segundo município com o maior número de escolas no campo.

Em todos os municípios de grande extensão territorial há problemas com a educação e identidade da escola do campo. A lógica que predomina é a da educação rural interrogada pela Educação do Campo, a exemplo do que discutimos em Souza (2016b), em que é frágil a relação entre equipes pedagógicas e as comunidades rurais, bem como é forte o incentivo do poder local para que as escolas do campo sejam fechadas, em particular as que são multisseriadas. As linhas de transporte escolar possuem milhares de quilômetros percorridos diariamente, com orçamentos anuais milionários. Portanto, o problema central é o condicionante estrutural histórico, concentração da terra, que tem determinado processos sociais conhecidos como de exclusão no campo, embora sejam expressão da contradição capital x trabalho e do projeto político hegemônico no país. Há municípios em que o poder executivo está nas mãos de quem detém a propriedade da terra, e a coisa pública torna-se tratada como se privada fosse. As relações clientelistas são comuns nessas regiões, e a educação e a política de transporte escolar rural não fogem à regra.

Portanto, investigar as microrregiões, localizando os sujeitos que nelas vivem e as condições de trabalho, conflitos, uso da terra e da propriedade é importante para compreendermos os processos que marcam a pauta e a política educacional local, em que pese ela ser determinada, em grande medida, pela esfera estadual e nacional, que se somam aos determinantes econômicos e financeiros internacionais.

As escolas públicas podem ser lugares de valorização do território local e da identidade dos povos que nelas estudam. Essa é uma das lutas empreendidas por movimentos sociais no Brasil, escola pública, gratuita e de qualidade.

\section{REFERÊNCIAS}

BRASIL. Lei n. 9.394, de 20 de dezembro de 1996. Estabelece as diretrizes e bases da educação nacional. Diário Oficial da União: Seção 1, Brasília, DF, p. 27833, 23 dez. 1996. PL 1258/1988

BRASIL. Lei n. 12.960 de março de 2014. Altera a Lei no 9.394, de 20 de dezembro de 1996, que estabelece as diretrizes e bases da educação nacional, para fazer constar a exigência de manifestação de órgão normativo do sistema de ensino para o fechamento de escolas do campo, indígenas e quilombolas. Diário Oficial da União: Seção 1, Brasília, DF, p. 1, 28 mar. 2014. PL 3534/2012

CALDART, R. S. Elementos para a construção de um projeto político e pedagógico da Educação do Campo. In: MOLINA, M. C.; JESUS, S. M. S. A. (Org.). Contribuições para a 
construção de um projeto de Educação do Campo. Brasília: Articulação Nacional por uma Educação do Campo, 2004. (Coleção Por uma Educação do Campo, 5)

CRUZ, R. A. Educação e contradição: disputas político-pedagógicas em torno da escola pública do campo. 2018. 217 f. Tese (Doutorado em Educação) - Universidade Tuiuti do Paraná, Curitiba, 2018.

FERNANDES, B. M.; WELCH, C. A.; GONÇALVES, E. C. Os usos da terra no Brasil. São Paulo: Cultura Acadêmica: Unesco, 2014.

FESTA, P. S. V. As interfaces educação especial e Educação do Campo: elementos constitutivos e o sujeito no discurso político-pedagógico na produção acadêmica e documental. 2020. 203 f. Tese (Doutorado em Educação) - Universidade Tuiuti do Paraná, Curitiba, 2020.

HAGE, S. A. M. Transgressão do paradigma da (multi)seriação como referência para a construção da escola pública do campo. Ed. \& Soc., Campinas, v. 35, n. 129, p. 1165-1182, out./dez. 2014. DOI: https://doi.org/10.1590/ES0101-73302014144531

IBGE. Instituto Brasileiro de Geografia e Estatística. Censo Demográfico de 2010. Rio de Janeiro, RJ: IBGE, 2010. Disponível em: www.ibge.gov.br/censo2010. Acesso em: 1 ago. 2020 .

IBGE. Instituto Brasileiro de Geografia e Estatística. Cidades e Estados. Rio de Janeiro, RJ: IBGE, 2020. Disponível em: https://www.ibge.gov.br/cidades-e-

estados.html?view=municipio. Acesso em: 20 nov. 2020.

INEP. Instituto Nacional de Estudos e Pesquisas Educacionais Anísio Teixeira. Catálogo de Escolas. Brasília, DF: INEP, 2020. Disponível em: https://inepdata.inep.gov.br/analytics/saw.dll?dashboard. Acesso em: 30 nov. 2020.

IPARDES. Instituto Paranaense de Desenvolvimento Econômico e Social. Cadernos Municipais, Curitiba, 2020. Disponível em: http://www.ipardes.pr.gov.br/Pagina/Cadernosmunicipais. Acesso em: 20 nov. 2020.

LIMA, R. C. R. Na contramão da Educação do Campo: programas de interesse do capital em disputa nas escolas públicas. 2020. 309 f. Tese (Doutorado em Educação) - Universidade Tuiuti do Paraná, Curitiba, 2020.

MACHADO, I. F.; VENDRAMINI, C. R. Políticas públicas para a Educação do Campo: da necessidade aos limites. Revista Ibero-Americana de Estudos em Educação, Araraquara, v. 8, n. 1, p. 1-16, 2013. DOI: https://doi.org/10.21723/riaee.v8i1.6470

MARIANO, A. S. Ensaios da escola do trabalho no contexto das lutas do MST: a proposta curricular dos ciclos de formação humana com complexos de estudo nas escolas itinerantes do Paraná. 2016. 255 f. Dissertação (Mestrado em Educação) - Universidade Estadual do Centro-Oeste do Paraná, Guarapuava, 2016.

NOZU, W. C. S.; BRUNO, M. M. G.; HEREDERO, E. S. Interface educação especial Educação do Campo: diretrizes políticas e produção do conhecimento no Brasil. Revista 
Ibero-Americana de Estudos em Educação, Araraquara, v. 11, n. 25, p. 489-502, 2016. DOI: https://doi.org/10.21723/RIAEE.v11.esp.1.p489

PAULA A. P. de. Relações entre Educação do Campo e o território: significados da escola da/na ilha para uma comunidade tradicional de Guaraqueçaba no litoral do Paraná. 2019. 257 f. Tese (Doutorado em Educação) - Universidade Federal do Paraná, Curitiba, 2019.

PEREIRA, C. C. A política de fechamento de escolas no campo na Região Metropolitana de Curitiba. 2017. 192 f. Dissertação (Mestrado em Educação) - Universidade Tuiuti do Paraná, Curitiba, 2017.

PIANOVSKI. R. B. Ensino e aprendizagem em escolas rurais multisseriadas e as contribuições da psicologia histórico-cultural e da pedagogia histórico-crítica. 2017. 225 f. Tese (Doutorado em Educação) - Universidade Tuiuti do Paraná, Curitiba, 2017.

REICHENBACH, V. Fechamento das escolas do campo no estado do Paraná (19972017): violação do direito a educação. 2019. 194 f. Dissertação (Mestrado em Educação) Universidade Federal do Paraná, Curitiba, 2019.

RODRIGUES, F. A. F. A prática pedagógica em turmas multisseriadas: processo de transgressão. 2017. 169 f. Dissertação (Mestrado em Educação) - Universidade Tuiuti do Paraná, Curitiba, 2017.

SANTOS, A. R. Internacionalização da pesquisa e produção do conhecimento sobre educação do campo da área da educação na região nordeste (2013 - 2020). Revista Práxis

Educacional, Vitória da Conquista, v. 16, n. 43, p. 196-228, Edição Especial, 2020. DOI: https://doi.org/10.22481/praxisedu.v16i43.7689

SOUZA, M. A. A Educação do Campo no Brasil. In: SOUZA, E. C.; CHAVES, V. L. J. (Org.). Documentação, memória e história da educação no Brasil: diálogos sobre políticas de educação e diversidade. Tubarão: Copiart, 2016b. v. 1, p. 133-157.

SOUZA, M. A. Educação e movimentos sociais do campo: a produção do conhecimento no período de 1987 a 2007. 2. ed. amp., atual. e rev. Curitiba: Editora da UFPR, 2016a.

SOUZA, M. A. Pesquisa educacional sobre MST e Educação do Campo no Brasil. Educação em Revista, Belo Horizonte, v. 36, e208881, 2020. DOI: http://dx.doi.org/10.1590/01024698208881

VERDE, V. V. Territórios, ruralidade e desenvolvimento. Curitiba: IPARDES, 2004. 


\section{Como referenciar este artigo}

SOUZA, M. A. Educação e contradição no campo: e as escolas públicas? Revista IberoAmericana de Estudos em Educação, v. 16, n. esp. 2, p. 1231-1252, maio 2021. e-ISSN: 1982-5587. DOI: https://doi.org/10.21723/riaee.v16iesp2.15123

Submissão em: $15 / 12 / 2020$

Revisões requeridas em: 28/01/2021

Aprovado em: 03/03/2021

Publicado em: 01/05/2021 